\title{
Phase I trial of axitinib combined with platinum doublets in patients with advanced non-small cell lung cancer and other solid tumours
}

\section{MF Kozloff ${ }^{*}, 1,2$, LP Martin ${ }^{3}$, M Krzakowski $^{4}$, TA Samuel ${ }^{5}$, TA Rado ${ }^{6}$, E Arriola ${ }^{7}$, J De Castro Carpeño ${ }^{8}$, RS Herbst ${ }^{9}$, J Tarazi ${ }^{10}$, S Kim ${ }^{10}$, B Rosbrook ${ }^{10}$, M Tortorici $^{10}$, AJ Olszanski ${ }^{10,11}$ and RB Cohen ${ }^{3}$}

'Section of Oncology/Hematology, Ingalls Hospital, Harvey, IL, USA; ${ }^{2}$ Department of Medicine, University of Chicago, Chicago, IL, USA; ${ }^{3}$ Department of Medical Oncology, Fox Chase Cancer Center, Philadelphia, PA, USA; ${ }^{4}$ The Maria Sklodowska-Curie Institute of Oncology, Warsaw, Poland; ${ }^{5}$ Department of Medical Oncology, Georgia Health Sciences University Cancer Center, Augusta, GA, USA; ${ }^{6}$ Clinical Research Department, Columbia Basin Hematology and Oncology, Kennewick, WA, USA; ${ }^{7}$ Medical Oncology Department, Hospital del Mar, Barcelona, Spain; ${ }^{8}$ University Hospital La Paz, Madrid, Spain; ${ }^{9}$ Department of Thoracic/Head and Neck Medical Oncology, MD Anderson Cancer Center, Houston, TX, USA; ${ }^{10}$ Pfizer Oncology, San Diego, CA, USA

\begin{abstract}
BACKGROUND: This phase I dose-finding trial evaluated safety, efficacy and pharmacokinetics of axitinib, a potent and selective secondgeneration inhibitor of vascular endothelial growth factor receptors, combined with platinum doublets in patients with advanced non-small cell lung cancer (NSCLC) and other solid tumours.

METHODS: In all, 49 patients received axitinib $5 \mathrm{mg}$ twice daily (b.i.d.) with paclitaxel/carboplatin or gemcitabine/cisplatin in 3-week cycles. Following determination of the maximum tolerated dose, a squamous cell NSCLC expansion cohort was enroled and received axitinib $5 \mathrm{mg}$ b.i.d. with paclitaxel/carboplatin.

RESULTS: Two patients experienced dose-limiting toxicities: febrile neutropenia $(n=1)$ in the paclitaxel/carboplatin cohort and fatigue $(n=1)$ in the gemcitabine/cisplatin cohort. Common nonhaematologic treatment-related adverse events were hypertension (36.7\%), diarrhoea (34.7\%) and fatigue (28.6\%). No grade $\geqslant 3$ haemoptysis occurred among 12 patients with squamous cell NSCLC. The objective response rate was $37.0 \%$ for patients receiving axitinib/paclitaxel/carboplatin $(n=27)$ and $23.8 \%$ for patients receiving axitinib/gemcitabine/cisplatin $(n=21)$. Pharmacokinetics of axitinib and chemotherapeutic agents were similar when administered alone or in combination.

CONCLUSION: Axitinib $5 \mathrm{mg}$ b.i.d. may be combined with standard paclitaxel/carboplatin or gemcitabine/cisplatin regimens without evidence of overt drug-drug interactions. Both combinations demonstrated clinical efficacy and were well tolerated.

British Journal of Cancer (2012) 107, 1277-1285. doi:10.1038/bjc.2012.406 www.bjcancer.com

Published online 18 September 2012

(C) 2012 Cancer Research UK
\end{abstract}

Keywords: axitinib; chemotherapy; pharmacokinetics; solid tumours; non-small cell lung cancer

New therapeutic strategies are needed to improve the efficacy of chemotherapy regimens for advanced solid tumours. For patients with advanced non-small cell lung cancer (NSCLC), platinumbased doublets remain a standard of care (Stinchcombe and Socinski, 2009). However, these treatments result in only modest improvements in survival (Burris, 2009). Addition of targeted agents, which act on specific signalling pathways involved in tumour progression, to chemotherapy regimens may improve clinical outcomes.

The vascular endothelial growth factor (VEGF) pathway has a key role in tumour-related angiogenesis, and its deregulation is characteristic of many solid tumours (Brown et al, 1993; Ikeda et al, 1999; Berns et al, 2003; Saad et al, 2004; Keedy and Sandler, 2007). Novel agents have been developed to target the VEGF ligand

\footnotetext{
*Correspondence: Dr MF Kozloff; E-mail: mfkozloff@aol.com

" Current address: Department of Medical Oncology, Fox Chase Cancer Center, Philadelphia, PA, USA

Received 24 February 2012; revised 30 July 2012; accepted 15 August 2012; published online 18 September 2012
}

or its receptor. In several phase III studies, inhibition of VEGF signalling by the anti-VEGF antibody bevacizumab in combination with chemotherapy improved patient outcomes compared with chemotherapy alone (Hurwitz et al, 2004; Sandler et al, 2006; Miller et al, 2007; Reck et al, 2010). In patients with advanced nonsquamous NSCLC, bevacizumab prolonged overall survival (OS) when combined with paclitaxel and carboplatin compared with chemotherapy alone (median OS, 12.3 vs 10.3 months) (Sandler et al, 2006), and prolonged progression-free survival, but not OS, when combined with gemcitabine and cisplatin (Reck et al, 2010). Investigation of antiangiogenic agents with different mechanisms of action, such as tyrosine kinase inhibition, in combination with chemotherapy is warranted. Results from a phase III study showed that adding sorafenib, an inhibitor of multiple tyrosine kinases, to carboplatin/paclitaxel did not prolong OS compared with chemotherapy alone in patients with NSCLC (Scagliotti et al, 2010). Nevertheless, other tyrosine kinase inhibitors that selectively inhibit VEGF receptors may still offer clinical benefit when added to chemotherapy.

Axitinib is an oral, potent and selective second-generation tyrosine kinase inhibitor of VEGF receptors 1, 2 and 3 (Hu-Lowe 
et al, 2008). When combined with docetaxel, carboplatin or gemcitabine in human tumour models, axitinib enhanced the antitumour efficacy of these agents (Hu-Lowe et al, 2008). In phase II studies of several tumour types, axitinib showed single-agent activity and was well tolerated (Rixe et al, 2007; Cohen et al, 2008; Rini et al, 2009; Schiller et al, 2009). In a phase II study of patients with advanced NSCLC receiving single-agent axitinib, median OS was 14.8 months (Schiller et al, 2009), which compares favourably with chemotherapy (Burris, 2009). These data suggest axitinib may enhance the efficacy of standard chemotherapy regimens for the treatment of selected solid tumours, including NSCLC.

Here, we report safety, efficacy and pharmacokinetic findings from a phase I study of combination treatment with axitinib plus paclitaxel/carboplatin or gemcitabine/cisplatin in patients with advanced solid tumours, including squamous cell NSCLC.

\section{PATIENTS AND METHODS}

\section{Study design and end points}

This was a phase I, open-label, multicentre, dose-finding study consisting of nine treatment cohorts, plus an expansion cohort of patients with squamous cell NSCLC who were enroled after determination of the maximum tolerated dose (MTD) of axitinib plus paclitaxel/carboplatin. Here, we report findings from cohorts that received axitinib in combination with either paclitaxel/ carboplatin (cohorts 1, 2 and 3 plus expansion) or gemcitabine/ cisplatin. Findings from other treatment cohorts are presented in an accompanying article (Martin et al, 2012). Primary end point was MTD of axitinib combined with either paclitaxel/carboplatin or gemcitabine/cisplatin. Secondary end points included safety, tumour response rates and plasma pharmacokinetic profiles.

This study was performed in accordance with the study protocol approved at each participating centre, International Conference on Harmonisation Guidelines on Good Clinical Practice and applicable local regulatory requirements and laws. All patients provided written informed consent. This trial is registered on ClinicalTrials.gov (NCT00454649).

\section{Patients}

Patients aged $\geqslant 18$ years with any histologically or cytologically proven advanced solid malignancy suitable for treatment with paclitaxel/carboplatin or gemcitabine/cisplatin were eligible. Inclusion criteria for all cohorts included an Eastern Cooperative Oncology Group performance status (ECOG PS) of 0 or 1; no preexisting uncontrolled hypertension (antihypertensive medications were permitted); adequate organ function; and no prior chemotherapy with platinum salts or taxanes for metastatic disease except as noted below; adjuvant treatment with platinum salts or taxanes must have been completed $\geqslant 12$ months before enrolment. For patients receiving gemcitabine/cisplatin, any type of previous chemotherapy was allowed and, for patients in the expansion cohort, any type of previous treatment was allowed. Patients with NSCLC with squamous cell histology, or mixed histology that was predominantly squamous, were eligible for the expansion cohort, which received axitinib plus paclitaxel/carboplatin.

Exclusion criteria included myocardial infarction, congestive heart failure, cerebrovascular accident (including transient ischaemic attack) or pulmonary embolus $<12$ months before enrolment; haemoptysis ( $>0.5$ teaspoon blood per day) within 1 week of enrolment; and at least one lung lesion with cavitation or any lesion invading and/or supporting large blood vessels.

\section{Study treatments}

Treatment schedules are shown in Figure 1. All patients received axitinib twice daily (b.i.d.) with food. In vitro studies indicate
A

Cohorts 1-3 (paclitaxel/carboplatin) cycles (3 weeks)
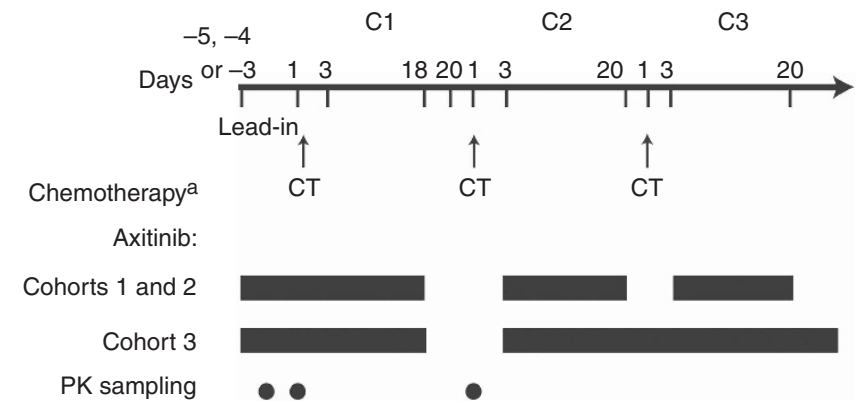

B

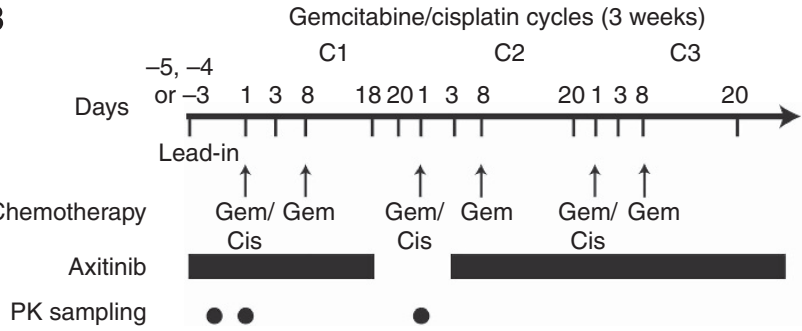

Figure I Treatment schedule for (A) paclitaxel/carboplatin cohorts and (B) gemcitabine/cisplatin cohort. ${ }^{\mathrm{a}}$ Chemotherapy $(\mathrm{CT})=$ paclitaxel/carboplatin for cohort I, 2 and 3. C= cycle; Cis = cisplatin; Gem = gemcitabine; $\mathrm{PK}=$ pharmacokinetic

Table I Axitinib dose escalation in patients receiving paclitaxel/ carboplatin

\begin{tabular}{llll}
\hline Cohort & $\begin{array}{l}\text { Lead-in dose of } \\
\text { axitinib (b.i.d.) }\end{array}$ & $\begin{array}{l}\text { Patients } \\
\text { enroled }(\boldsymbol{n})\end{array}$ & $\begin{array}{l}\text { Dose-limiting } \\
\text { toxicities }\end{array}$ \\
\hline 1 & $1 \mathrm{mg}^{\mathrm{a}}$ & 3 & None \\
2 & $3 \mathrm{mg}^{\mathrm{a}}$ & 5 & None \\
3 & $5 \mathrm{mg}$ & $20^{\mathrm{b}}$ & $\begin{array}{l}\text { Febrile neutropenia } \\
(n=1)\end{array}$ \\
& & & $(n)$
\end{tabular}

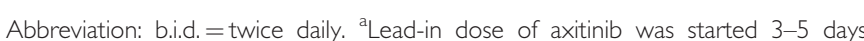
before the first dose of chemotherapy and continued for 2 days after the first chemotherapy dose (from day $-5,-4$ or -3 through cycle I day 2 ). ' Includes patients enroled in the expansion cohort.

axitinib noncompetitively inhibits the cytochrome P450 (CYP) 2C8 enzyme (unpublished data) involved in paclitaxel metabolism (Monsarrat et al, 1993; Steed and Sawyer, 2007). Owing to potential for drug-drug interactions between axitinib and paclitaxel, the axitinib lead-in dose was administered at 1,3 and $5 \mathrm{mg}$ b.i.d. for sequential cohorts 1, 2 and 3, respectively, started 3-5 days before the first dose of chemotherapy and continued for 2 days after the first chemotherapy dose. Cohorts 1, 2 and 3 were to enrol three to six patients, depending on the number of patients that experienced a dose-limiting toxicity (DLT) during the first cycle (Table 1). If none of the first three patients experienced a DLT during the first cycle, the lead-in dose of axitinib was escalated in the subsequent cohort. If one of the three patients experienced a DLT during the first cycle, the cohort was expanded to include a total of six patients, and if one of six patients experienced a DLT during the first cycle, the lead-in dose of axitinib was escalated in the next cohort. The lead-in dose of axitinib for the gemcitabine/cisplatin cohort was $5 \mathrm{mg}$ b.i.d. After the lead-in period, axitinib $5 \mathrm{mg}$ b.i.d. was administered continuously in all cohorts. Axitinib was interrupted 3 days before cycle 2 day 1 of chemotherapy administration and dosing was resumed on cycle 2 day 3; for cohorts 1 and 2, starting with cycle 2, axitinib was interrupted 1 day before chemotherapy infusion (day 21) and resumed on day 3 of each subsequent cycle. For the expansion cohort, axitinib was 
administered at the MTD defined in cohorts 1-3, beginning cycle 1 day 1. All patients continued treatment with axitinib until disease progression or unacceptable toxicity. After cycle 1, patients with no grade $>2$ adverse events (AEs) related to axitinib for consecutive 2-week periods could have their axitinib dose titrated to $7 \mathrm{mg}$ b.i.d. and then to a maximum of $10 \mathrm{mg}$ b.i.d., unless BP measured $>150 / 100 \mathrm{~mm} \mathrm{Hg}$ or the patient was receiving antihypertensive medication. The axitinib dose was reduced to $3 \mathrm{mg}$ b.i.d., and then to $2 \mathrm{mg}$ b.i.d. in patients with grade $\geqslant 3$ nonhaematologic treatment-related AEs. For patients who developed systolic BP >150 mm Hg or diastolic BP >100 mm Hg, new or additional antihypertensive therapy was started or the dose of existing medication increased. If patients developed haemoptysis ( $>0.5$ teaspoon of bright red blood per day), axitinib was discontinued and a radiologic assessment was to be considered. For patients in the squamous cell NSCLC expansion cohort who developed cavitation after enrolment, axitinib was withheld and patients were assessed on a case-by-case basis. Patients who permanently discontinued axitinib because of toxicity could continue to receive chemotherapy as long as treatment was considered clinically beneficial.

Patients in cohorts 1-3 and the expansion cohort received paclitaxel ( $200 \mathrm{mg} \mathrm{m}^{-2}$; 3-h infusion) followed by carboplatin (area under the plasma concentration-time curve (AUC) target of $6 \mathrm{mg} \mathrm{min} \mathrm{ml}^{-1}$; 30 -min infusion) every 3 weeks. Patients in the gemcitabine/cisplatin cohort received cisplatin $\left(80 \mathrm{mg} \mathrm{m}^{-2}\right.$ on day 1) and gemcitabine (1250 $\mathrm{mg} \mathrm{m}^{-2}$ on days 1 and 8 ; 30 -min infusion), followed by a 1-week rest period, in 3-week cycles. Chemotherapy regimens were modified on an individual basis according to patient tolerability at the discretion of the investigator. Paclitaxel/ carboplatin was delayed in patients with absolute granulocyte counts $<1500$ cells $\mathrm{mm}^{-3}$ or platelet counts $<100000$ cells mm $^{-3}$ and discontinued if recovery did not occur after 4 weeks. Paclitaxel/carboplatin was withheld in patients with grade $\geqslant 3$ haematologic or nonhaematologic toxicities and resumed at one lower dose level when the toxicity was grade $\leqslant 1$. Paclitaxel was reduced in patients with grade 2 neurotoxicity or withheld until neurotoxicity was grade $\leqslant 1$. The gemcitabine/cisplatin dose was reduced to $75 \%$ in patients with febrile neutropenia, grade 4 neutropenia for $\geqslant 7$ days, grade 4 thrombocytopenia, bleeding grade $>2$ with grade 3 thrombocytopenia or grade 3 nonhaematologic toxicities during the prior cycle. The gemcitabine/cisplatin dose was reduced to $50 \%$ or delayed in patients with grade 4 nonhaematologic toxicities during the prior cycle. Gemcitabine/ cisplatin was delayed by 1 week if the absolute neutrophil count was $<1.0 \times 10^{9} 1^{-1}$ and/or the platelet count was $<100 \times 10^{9} 1^{-1}$. If on day 8 , the absolute neutrophil count was $<1.0 \times 10^{9} 1^{-1}$ and/or the platelet count was $<100 \times 10^{9} 1^{-1}$, gemcitabine was not administered. Cisplatin was discontinued in patients with grade $\geqslant 2$ peripheral neurotoxicity, tinnitus or hearing loss during the prior cycle. Prophylactic use of colony-stimulating factors was permitted in patients who experienced infection or grade 4 neutropenia during the previous cycle. Patients who discontinued chemotherapy because of toxicity or because they completed the maximum number of cycles according to institutional practice could continue to receive axitinib as a single agent.

\section{Assessments}

The MTD for axitinib plus paclitaxel/carboplatin or gemcitabine/ cisplatin was defined as the dose level at which no more than one of the first six patients enroled in each cohort experienced a DLT during the first cycle of therapy, with two or more of the six patients experiencing a DLT at the next highest dose level. If the MTD was not exceeded within the planned dose levels, MTD was defined as the maximum dose tested. Dose-limiting toxicities were defined as grade 4 neutropenia or thrombocytopenia for $\geqslant 14$ days, or grade 4 febrile neutropenia; proteinuria $\geqslant 2 \mathrm{~g} / 24 \mathrm{~h}$; haemoptysis ( $\geqslant 0.5$ teaspoon per day) for $\geqslant 7$ days; uncontrolled grade $\geqslant 3$ nonhaematologic toxicity for $\geqslant 7$ days; or inability to resume study treatment within 14 days after stopping because of axitinib-related toxicity.

Safety was monitored throughout the study, and AE severity was graded according to the Common Terminology Criteria for Adverse Events, version 3.0 (Trotti et al, 2003). Physical examinations, assessment of ECOG PS, chest X-rays and laboratory tests were conducted at baseline, day 1 of each cycle and at followup (28 days after the last dose). Additional physical examinations and haematology tests were performed at days 8 and 15 of each cycle. For the squamous cell NSCLC expansion cohort, chest $\mathrm{X}$-rays were performed to assess tumour cavitation on evennumbered cycles when other tumour assessments were not performed. BP was monitored at each clinic visit, and patients were issued a home BP monitoring device and diary and asked to record their $\mathrm{BP}$ at least twice daily before each axitinib dose. Patients were instructed to contact their physicians for systolic $\mathrm{BP}>150 \mathrm{~mm} \mathrm{Hg}$ or diastolic BP $>100 \mathrm{~mm} \mathrm{Hg}$. Home BP measurements were not used for DLT assessments. Tumours were radiologically assessed every two cycles, according to Response Evaluation Criteria in Solid Tumours (RECIST version 1.0) (Therasse et al, 2000).

\section{Pharmacokinetic analysis}

The pharmacokinetics of steady-state axitinib alone and chemotherapy alone, as well as the combination of steady-state axitinib plus chemotherapy, were evaluated in each patient in all cohorts except the expansion cohort. Pharmacokinetics of steadystate axitinib when administered alone were determined using blood samples collected pre-dose and 1,2, 3, 4, 6 and $8 \mathrm{~h}$ after dosing on cycle 1 day -1 . Pharmacokinetics of chemotherapy when administered alone were determined using blood samples collected on cycle 2 day 1 . Pharmacokinetics of the combination of steadystate axitinib and chemotherapy were determined using blood samples collected on cycle 1 day 1 . Samples for paclitaxel/ carboplatin analysis were collected pre-dose and 1, 2, 3, 3.25, 3.5, $4,5,6,8,24$ and $30 \mathrm{~h}$ after the start of paclitaxel infusion. Samples for gemcitabine analysis were collected pre-dose and 0.25, 0.5, 0.75, $1,1.25,1.5,2,3$ and $4 \mathrm{~h}$ after the start of infusion in tubes containing tetrahydrouridine, which prevented continued metabolism of gemcitabine during the processing of samples. Samples for cisplatin analysis were collected pre-dose and $0.5,1,1.5,2.5$, $3.5,5.5$ and $7.5 \mathrm{~h}$ after the start of infusion.

Plasma concentrations of axitinib were measured using a validated high-performance liquid chromatography with tandem mass spectrometric detection method (LC/MS/MS) (Charles River Discovery and Development Services; Shrewsbury, MA, USA) (Rugo et al, 2005). Concentrations of paclitaxel, gemcitabine and the gemcitabine metabolite $2^{\prime}, 2^{\prime}$-difluorodeoxyuridine $(\mathrm{dFdU})$ in sodium heparin plasma were measured using a validated LC/MS/ MS assay (Covance Bioanalytical Services; Indianapolis, IN, USA) with ranges of $10-2000 \mathrm{ng} \mathrm{ml}^{-1}, \quad 50-50000 \mathrm{ng} \mathrm{ml}^{-1}$ and $500-50000 \mathrm{ng} \mathrm{ml}^{-1}$ for paclitaxel, gemcitabine and dFdU, respectively. Concentrations of platinum from carboplatin and cisplatin in sodium heparin plasma and plasma ultrafiltrate (PUF) were measured using a validated inductively coupled plasma-MS assay (Covance Laboratories; Madison, WI, USA) with ranges of 2.0-1000 $\mathrm{ng} \mathrm{ml}^{-1}$ and $1.0-500 \mathrm{ng} \mathrm{m}^{-1}$ in plasma and PUF, respectively. All pharmacokinetic analyses were conducted using WinNonlin Professional (version 4.01, Pharsight Corp.; Mountain View, CA, USA).

\section{Statistical analysis}

All patients receiving at least one dose of study medication were included in the safety analysis. Patients having one or more target 
lesion according to RECIST and a baseline assessment of disease and who received at least one dose of study medication were included in the analysis of best objective response. Data were summarised using means, medians, s.d. and ranges for continuous data and frequencies and percentages for categorical data.

\section{RESULTS}

\section{Patient demographics and disposition}

In all, 49 patients were enroled, including 28 patients in the paclitaxel/carboplatin cohorts and 21 patients in the gemcitabine/ cisplatin cohort (Table 2). The most common tumour type was NSCLC in 17 patients (34.7\%), all of whom were in the paclitaxel/ carboplatin cohorts.

Study treatment duration for individual patients is shown in Figure 2. Patients received axitinib for a median of 174 days (range 10-656) and 89 days (range 5-992) in the paclitaxel/carboplatin and gemcitabine/cisplatin cohorts, respectively. The median daily axitinib dose was $9.8 \mathrm{mg}$ (range 4.7-15.1) in patients receiving paclitaxel/carboplatin and $9.0 \mathrm{mg}$ (range 6.0-10.0) in patients receiving gemcitabine/cisplatin. Dosing of axitinib was reduced in 16 patients $(35.7 \%$ and $28.6 \%$ of patients in the paclitaxel/ carboplatin and gemcitabine/cisplatin cohorts, respectively) and was interrupted in 24 patients $35.7 \%$ and $66.7 \%$ of patients in the paclitaxel/carboplatin and gemcitabine/cisplatin cohorts, respectively). Median number of paclitaxel/carboplatin cycles was 6, 5 and 4 (range 1-6) for cohorts 1,2 and 3, respectively; median number of chemotherapy cycles was 4 (range 1-29) and 3 (range 1-9) for gemcitabine and cisplatin, respectively. A total of 26 patients receiving axitinib plus paclitaxel/carboplatin discontinued the study, including 14 patients because of insufficient clinical response, 4 patients because of AEs and 8 patients for other reasons. In the gemcitabine/cisplatin cohort, 20 patients discontinued, including 10 because of insufficient clinical response, 6 because of AEs and 4 for other reasons.

\section{DLTs and MTD}

One of the first six patients in cohort 3 receiving axitinib/ paclitaxel/carboplatin experienced a DLT of febrile neutropenia during the first cycle (Table 1), and the MTD was determined to be axitinib $5 \mathrm{mg}$ b.i.d. continuously in combination with paclitaxel $200 \mathrm{mg} \mathrm{m}^{-2}$ and carboplatin (AUC $6 \mathrm{mg} \mathrm{min} \mathrm{ml}^{-1}$ ). One of the first six patients receiving axitinib/gemcitabine/cisplatin experienced a DLT of fatigue during the first cycle; the MTD was determined to be axitinib $5 \mathrm{mg}$ b.i.d. continuously in combination with cisplatin $80 \mathrm{mg} \mathrm{m}^{-2}$ (day 1) and gemcitabine $1250 \mathrm{mg} \mathrm{m}^{-2}$ (days 1 and 8). Dose titration to $10 \mathrm{mg}$ b.i.d. was achieved in three patients receiving paclitaxel/carboplatin.

\section{Safety and tolerability}

Six patients discontinued the study because of treatment-related AEs, which were fatigue, cerebrovascular accident and haemoptysis $(n=1$ each $)$ in the paclitaxel/carboplatin cohorts and hypertension $(n=2)$ and cerebrovascular accident $(n=1)$ in the gemcitabine/cisplatin cohort. Common treatment-related nonhaematologic AEs were hypertension $(n=18 ; 36.7 \%)$, diarrhoea $(n=17 ; 34.7 \%)$ and fatigue $(n=14 ; 28.6 \%)$ (Table 3$)$. Common grade $\geqslant 3$ treatment-related nonhaematologic AEs across both treatment arms were fatigue $(n=5 ; 10.2 \%)$ and hypertension $(n=5 ; 10.2 \%)$. In addition to the patient in cohort 3 receiving axitinib/paclitaxel/carboplatin who had a DLT of febrile neutropenia during the first cycle, one patient in cohort 2 experienced grade 4 febrile neutropenia; chemotherapy was reduced in this patient. In the paclitaxel/carboplatin cohorts, two patients $(7.1 \%)$ developed treatment-related stomatitis; both cases were classified
Table 2 Patient baseline characteristics

\begin{tabular}{lcc}
\hline & \multicolumn{2}{c}{ Axitinib +} \\
\cline { 2 - 3 } & $\begin{array}{c}\text { Paclitaxel/ } \\
\text { carboplatin, } \\
\mathbf{n = 2 8}\end{array}$ & $\begin{array}{c}\text { Gemcitabine/ } \\
\text { cisplatin, } \\
\mathbf{n = 2 ~ I ~ I ~}\end{array}$ \\
\hline Male/female, $n$ & $21 / 7$ & $9 / 12$ \\
Age, median (range), years & $60(37-75)$ & $52(40-79)$ \\
ECOG PS 0/I, $n$ & $16 / 12$ & $9 / 12$ \\
Primary tumour type, $n$ (\%) & & \\
NSCLC & $17(60.7)$ & 0 \\
Melanoma & $4(14.3)$ & 0 \\
Ovarian & $3(10.7)$ & $1(4.8)$ \\
Pancreatic & 0 & $4(19.0)$ \\
Breast & 0 & $3(14.3)$ \\
Head and neck & $1(3.6)$ & $1(4.8)$ \\
Cholangiocarcinoma & 0 & $2(9.5)$ \\
CRC & 0 & $2(9.5)$ \\
Other & $3(10.7)^{\mathrm{a}}$ & $8(38.1)^{\mathrm{b}}$ \\
Prior therapy, n (\%) & & \\
Surgery & $14(50.0)$ & $20(95.2)$ \\
Radiotherapy & $5(17.9)$ & $9(42.9)$ \\
Drug therapy & $8(28.6)$ & $15(71.4)$ \\
& &
\end{tabular}

Abbreviations: $\mathrm{CRC}=$ colorectal cancer; ECOG PS = Eastern Cooperative Oncology Group performance status; $N S C L C=$ non-small cell lung cancer. ${ }^{\text {aRenal }}$ cell carcinoma, unknown primary tumour $(n=2)$. bBladder, cervical, ectopic hormone secretion syndrome associated with neoplasia, gastrointestinal, prostate, sarcoma, small intestine, unknown primary tumour. Includes cytotoxic chemotherapy and targeted agents.

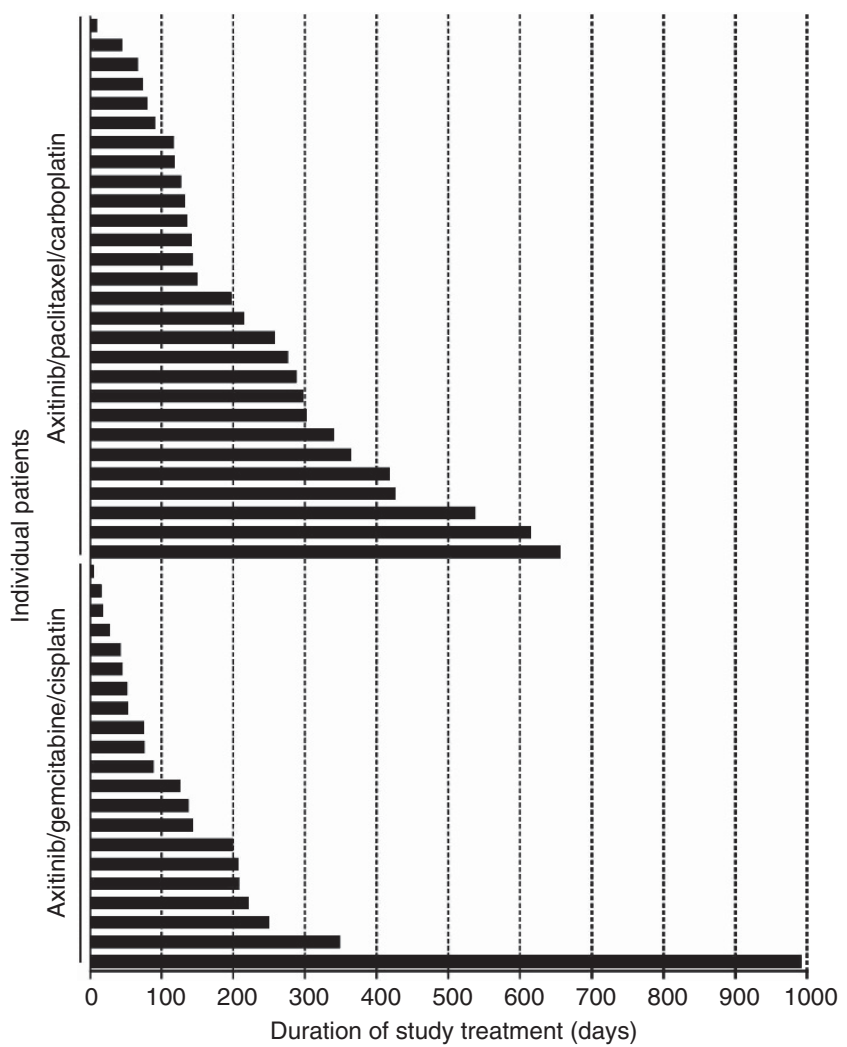

Figure 2 Duration of study treatment. 
Table 3 Safety and tolerability findings

(A) Treatment-related nonhaematologic AEs, ${ }^{a}$ n (\%)

\begin{tabular}{|c|c|c|c|c|c|}
\hline & \multirow{3}{*}{$\begin{array}{c}\text { Total, } N=49 \\
\text { All grades }\end{array}$} & \multicolumn{4}{|c|}{ Axitinib +} \\
\hline & & \multicolumn{2}{|c|}{ Paclitaxel/carboplatin, $n=28$} & \multicolumn{2}{|c|}{ Gemcitabine/cisplatin, $\boldsymbol{n}=\mathbf{2}$ I } \\
\hline & & All grades & Grade $3 / 4^{b}$ & All grades & Grade $3 / 4^{b}$ \\
\hline Hypertension & $18(36.7)$ & $10(35.7)$ & I (3.6) & $8(38.1)$ & $4(19.1)$ \\
\hline Diarrhoea & $17(34.7)$ & II (39.3) & I (3.6) & $6(28.6)$ & I (4.8) \\
\hline Fatigue & $14(28.6)$ & $9(32.1)$ & $4(14.3)$ & $5(23.8)$ & I (4.8) \\
\hline Proteinuria & $10(20.4)$ & $7(25.0)$ & I (3.6) & $3(14.3)$ & 0 \\
\hline Hand-foot syndrome & $9(18.4)$ & $8(28.6)$ & I (3.6) & I (4.8) & I (4.8) \\
\hline Epistaxis & $8(16.3)$ & $5(17.9)$ & 0 & $3(14.3)$ & 0 \\
\hline Nausea & $8(16.3)$ & 0 & 0 & $8(38.1)$ & 0 \\
\hline Decreased appetite & $7(14.3)$ & $3(10.7)$ & 0 & $4(19.1)$ & 0 \\
\hline Headache & $7(14.3)$ & I (3.6) & 0 & $6(28.6)$ & I (4.8) \\
\hline Rash & $7(\mid 4.3)$ & $5(17.9)$ & I (3.6) & $2(9.5)$ & I (4.8) \\
\hline Dysphonia & $7(14.3)$ & $4(14.3)$ & 0 & $3(14.3)$ & 0 \\
\hline Dysgeusia & $6(12.2)$ & $4(14.3)$ & 0 & $2(9.5)$ & 0 \\
\hline Dizziness & $5(10.2)$ & $4(14.3)$ & 0 & I (4.8) & 0 \\
\hline
\end{tabular}

(B) Haematologic laboratory abnormalities, $n$ (\%)

\begin{tabular}{|c|c|c|c|c|c|}
\hline & \multirow{3}{*}{$\begin{array}{l}\text { Total, } N=48 \\
\text { All grades }\end{array}$} & \multicolumn{4}{|c|}{ Axitinib +} \\
\hline & & \multicolumn{2}{|c|}{ Paclitaxel/carboplatin, $\mathbf{n}=\mathbf{2 7}$} & \multicolumn{2}{|c|}{ Gemcitabine/cisplatin, $n=2$ I } \\
\hline & & All grades & Grade $3 / 4^{b}$ & All grades & Grade $3 / 4^{b}$ \\
\hline Anaemia & $48(100)$ & $27(100)$ & $0(0)$ & $21(100)$ & $2(9.5)$ \\
\hline Neutropenia & $46(95.8)$ & $26(96.3)$ & $25(92.6)$ & $20(95.2)$ & $13(61.9)$ \\
\hline Leukopenia & $46(95.8)$ & $26(96.3)$ & $10(37.0)$ & $20(95.2)$ & $10(47.6)$ \\
\hline Thrombocytopenia & $43(89.6)$ & $25(92.6)$ & $7(25.9)$ & $18(85.7)$ & $10(47.6)$ \\
\hline Lymphopenia & $40(83.3)$ & $19(70.4)$ & $5(18.5)$ & $21(100)$ & $14(66.7)$ \\
\hline
\end{tabular}

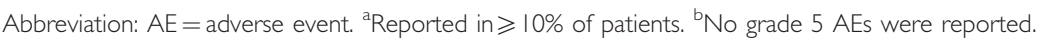

as grade 2 . No cases of grade $\geqslant 3$ haemoptysis or grade 5 treatmentrelated AEs were reported.

Haematologic laboratory abnormalities occurred in most patients (Table 3). With the exceptions of lymphopenia in the gemcitabine/cisplatin cohort and neutropenia in both cohorts, the majority of abnormalities were grade $\leqslant 2$. Grade $3 / 4$ treatmentrelated abnormalities reported as AEs were thrombocytopenia $(n=4 ; 8.2 \%)$, neutropenia $(n=2 ; 4.1 \%)$ and anaemia and leukopenia $(n=1$ each; $2.0 \%)$.

\section{Clinical activity}

Of the evaluable patients, $15(31.3 \%)$ achieved an objective response (Table 4), including 3 complete responses $(6.3 \%)$. An additional 16 patients $(33.3 \%)$ had stable disease for $>8$ weeks. Objective responses were observed in patients with NSCLC $(n=5)$, ovarian cancer $(n=3)$, melanoma $(n=2)$ and other tumour types $(n=5)$.

\section{Pharmacokinetic results}

Plasma pharmacokinetic parameters (maximum plasma concentration, AUC, clearance and volume of distribution) for paclitaxel, carboplatin, gemcitabine and its metabolite dFdU and cisplatin were similar in the absence or presence of axitinib (Table 5; Figure 3). Axitinib pharmacokinetic parameters were similar in the absence or presence of co-administered paclitaxel/carboplatin or gemcitabine/cisplatin (Table 5; Figure 3).
Table 4 Best response to therapy, by RECIST ${ }^{a}$

\begin{tabular}{lcc}
\hline & \multicolumn{2}{c}{$\mathbf{n}(\%)$} \\
Axitinib + \\
\cline { 2 - 3 } & \multicolumn{2}{c}{$\begin{array}{c}\text { Paclitaxel/carboplatin, } \\
\mathbf{n}=\mathbf{2 7}\end{array}$} \\
\hline Objective response rate $^{\mathrm{b}}$ & $10(37.0)$ & $\mathbf{n}=\mathbf{2} \mathbf{~ I}$ \\
Complete response $_{\text {Partial response }}$ & $2(7.4)$ & $5(23.8)$ \\
Stable disease & $8(29.6)$ & $4(19.8)$ \\
Disease progression & $11(40.7)$ & $5(23.8)$ \\
Indeterminate/missing & $3(11.1)$ & $3(14.3)$ \\
& $3(11.1)$ & $8(38.1)$ \\
\hline
\end{tabular}

Abbreviation: RECIST $=$ Response Evaluation Criteria in Solid Tumours. ${ }^{a}$ Includes treated patients with at least one target lesion according to RECIST and a baseline assessment of disease. ${ }^{b}$ Complete responses + partial responses.

\section{DISCUSSION}

Combination treatment with chemotherapy and an agent targeting the VEGF pathway has been shown to improve clinical outcome for several tumour types compared with chemotherapy alone (Hurwitz et al, 2004; Sandler et al, 2006; Miller et al, 2007; Reck et al, 2010). In this study, axitinib combined with paclitaxel/carboplatin or gemcitabine/cisplatin was well tolerated and demonstrated clinical 
Table 5 Plasma pharmacokinetic parameters of (A) paclitaxel, carboplatin, gemcitabine and cisplatin in the absence or presence of axitinib and (B) axitinib in the absence or presence of paclitaxel, carboplatin, gemcitabine and cisplatin

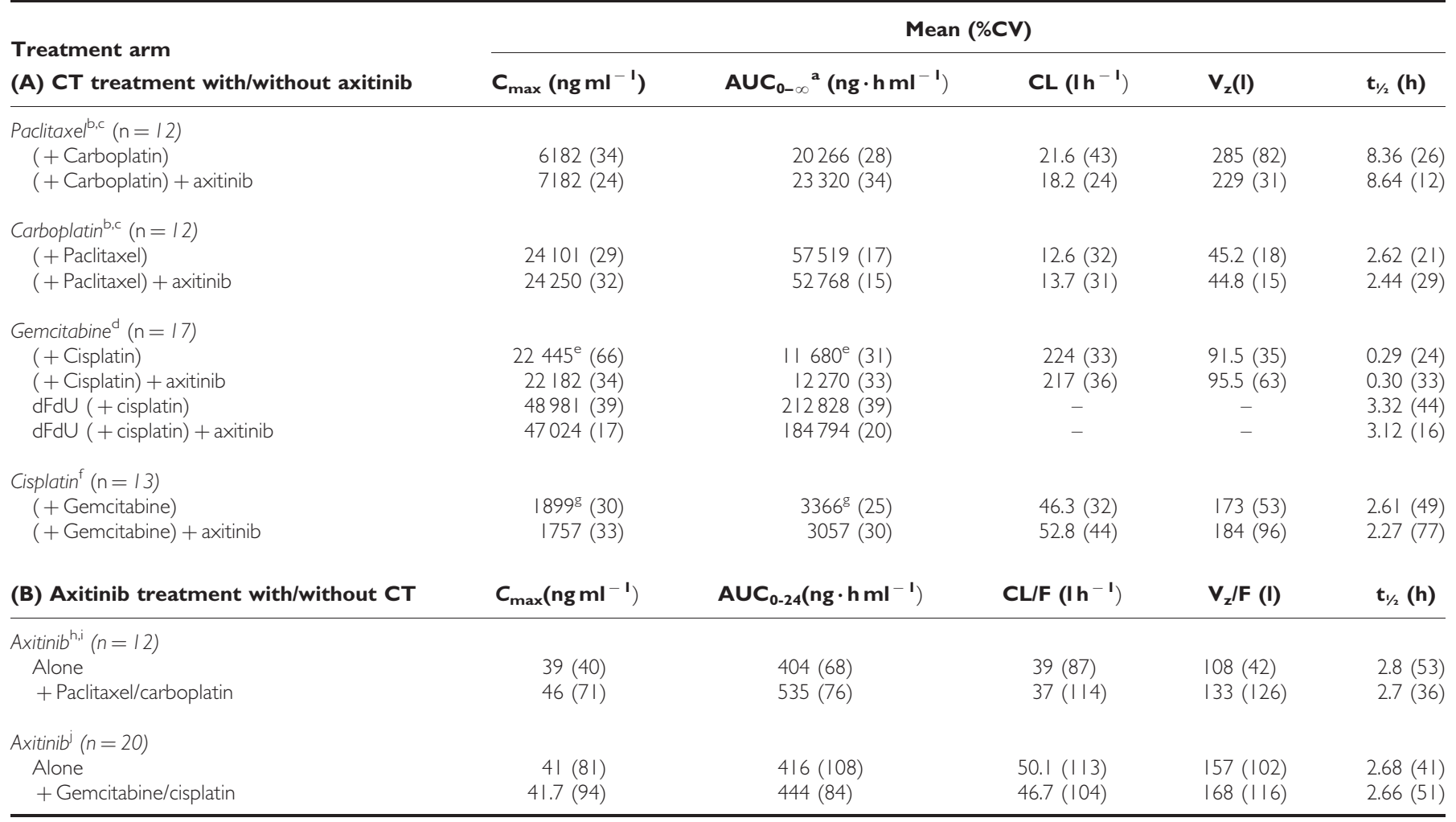

Abbreviations: $\mathrm{AUC}_{0-24}=$ area under the plasma concentration-time curve (AUC) from time 0 to $24 \mathrm{~h}$; $A \cup C_{0-\infty}=A \cup C$ from time zero to infinity; b.i.d. $=$ twice daily; $\mathrm{CL}=$ plasma clearance; $\mathrm{CL} / \mathrm{F}=$ apparent oral plasma clearance; $C_{\max }=$ maximum plasma concentration; $C T=$ chemotherapy; $C V=$ coefficient of variation; $\mathrm{dFdU}=2^{\prime}, 2^{\prime}$ difluorodeoxyuridine; $\mathrm{PK}=$ pharmacokinetic; PUF = plasma ultrafiltrate; $t_{1 / 2}=$ plasma terminal elimination half-life; $V_{z}=$ volume of distribution of the drug during the elimination phase; $V_{\mathrm{z}} / \mathrm{F}=$ apparent oral volume of distribution during the elimination phase. ${ }^{\mathrm{a}} \mathrm{AUC}$ reported for cisplatin is from time 0 to $8 \mathrm{~h}$. ${ }^{\mathrm{b}} \mathrm{Pooled}$ data from cohorts $\mathrm{I}-3$. PK parameters for carboplatin are in PUF. 'Two patients excluded because PK samples were not collected on cycle I day I. 'Four patients excluded because matching cycle I and cycle 2 PK evaluations were not completed. ${ }^{e} \mathrm{C}_{\max }$ and $\mathrm{AUC}_{0-\infty}$ on cycle 2 dose-normalised for patients who underwent gemcitabine dose reduction on cycle 2 compared with cycle 1 . fSeven patients excluded because matching cycle I and cycle 2 PK evaluations were not completed; one patient excluded because of non-estimable half-life; one patient excluded because of dose infusion interruption. PK parameters for cisplatin are in PUF. ${ }^{g} C_{\max }$ and $\mathrm{AUC}_{0-8}$ on cycle 2 dose-normalised for patients who underwent cisplatin dose reduction on cycle 2 compared with cycle I. ' $D$ ata were pooled from patients in cohorts I, 2 and 3 who received I, 3 and 5 mg b.i.d. doses of axitinib, respectively. Data were dosenormalised to $5 \mathrm{mg}$ b.i.d. 'For three patients, $\mathrm{AUC}_{0-24}, \mathrm{CL} / \mathrm{F}, \mathrm{V}_{\mathrm{z}} / \mathrm{F}$ and $\mathrm{t}_{1 / 2}$ were not reported because of non-estimable half-life. ${ }^{\mathrm{j}} \mathrm{O}$ ne patient excluded because matching cycle I and cycle 2 PK evaluations were not completed; for five patients $A \cup C_{0-24}, C L / F, V_{z} / F$, and $t_{1 / 2}$ were not reported because of non-estimable half-life.

efficacy without any overt pharmacokinetic interactions for various advanced solid tumours. The MTD for axitinib in combination with paclitaxel/carboplatin or gemcitabine/cisplatin was $5 \mathrm{mg}$ b.i.d.; however, further dose escalation of axitinib was achieved in some patients tolerating $5 \mathrm{mg}$ b.i.d.

Most AEs reported in this study were of mild-to-moderate grade, and the most common treatment-related nonhaematologic, grade $\geqslant 3$ AEs (hypertension, diarrhoea and fatigue) were anticipated, based on results from prior phase II studies of axitinib (Rixe et al, 2007; Cohen et al, 2008; Spano et al, 2008; Rini et al, 2009; Schiller et al, 2009). Unlike DLTs observed with other VEGF receptor tyrosine kinase inhibitors, for example, sorafenib, where skin toxicities such as rash and hand-foot syndrome were predominant (Moore et al, 2005; Strumberg et al, 2005), DLTs associated with axitinib in combination with paclitaxel/carboplatin or gemcitabine/cisplatin were febrile neutropenia and fatigue. Potential overlapping toxicities between axitinib and the chemotherapeutic agents, such as fatigue, nausea, diarrhoea and stomatitis, did not appear to be appreciably exacerbated.

Patients receiving anti-VEGF therapies have an increased risk of developing hypertension (Jain and Townsend, 2007; Zhu et al, 2007; Wu et al, 2008), and the incidence of hypertension in this study was consistent with previous axitinib trials (Rixe et al, 2007; Cohen et al, 2008; Rini et al, 2009; Schiller et al, 2009). Moreover, grade $\geqslant 3$ hypertension reported here was comparable to that reported in phase III studies in various advanced solid tumours treated with the VEGF inhibitor bevacizumab plus chemotherapy (4-14.8\%) (Sandler et al, 2006; Miller et al, 2007; Saltz et al, 2008). These data favour the use of antihypertensive medication and suggest the possible need for axitinib dose adjustments in patients who develop hypertension while receiving axitinib plus chemotherapy.

Of note, no cases of grade $\geqslant 3$ haemoptysis were reported in this study, although mild haemoptysis was reported in one patient who received axitinib plus paclitaxel/carboplatin. Bevacizumab is contraindicated in patients with squamous cell NSCLC because of the incidence of severe or fatal pulmonary haemorrhage (2004); thus, patients with squamous cell NSCLC were excluded from the phase III study evaluating bevacizumab combined with paclitaxel and carboplatin for NSCLC (Sandler et al, 2006). In this study, additional eligibility requirements, for example, exclusion of patients who had blood vessels with possible tumour involvement, may have mitigated, in part, the potential risk of haemoptysis. It will require further investigation in a larger study to confirm whether axitinib plus chemotherapy may be safely administered to patients with squamous cell NSCLC. A phase II trial (NCT00735904) evaluating axitinib combined with gemcitabine/ cisplatin for squamous cell NSCLC was recently completed. 
A
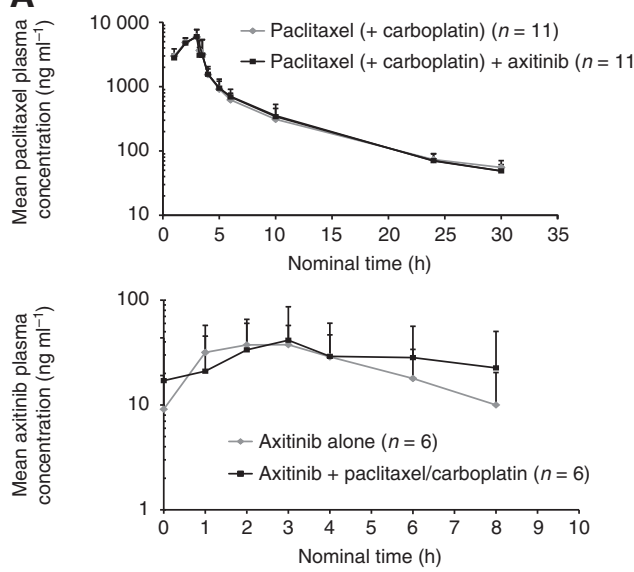

B
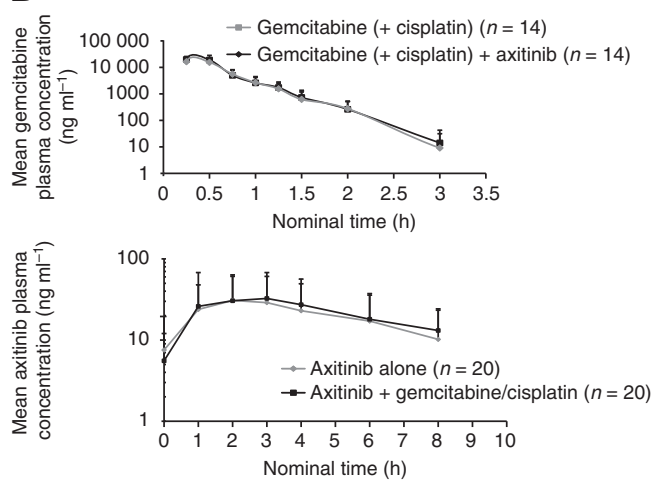
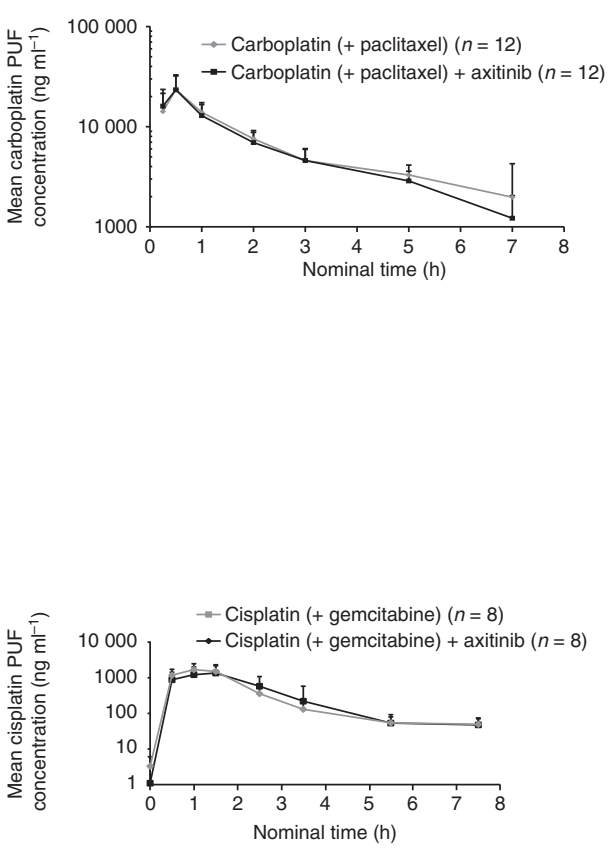

axitinib, gemcitabine and cisplatin. Abbreviation:

Figure 3 Plasma concent
PUF = plasma ultrafiltrate.

Data reported here suggest the ability to administer paclitaxel/ carboplatin or gemcitabine/cisplatin with axitinib without altering pharmacokinetics of these agents. Axitinib metabolism is primarily mediated by CYP3A4 and to a lesser extent by CYP1A2, CYP2C19 and UDP-glucuronosyltransferase $1 \mathrm{~A} 1$ as determined from in vitro studies with human liver microsomes (unpublished data). In vitro studies indicate that axitinib competitively inhibits CYP1A2 and non-competitively inhibits CYP2C8 with inhibitor constants of $0.7 \mu \mathrm{M} \quad\left(0.27 \mu \mathrm{g} \mathrm{ml}^{-1}\right)$ and $0.5 \mu \mathrm{M} \quad\left(0.19 \mu \mathrm{g} \mathrm{ml}^{-1}\right)$, respectively (unpublished data). Since paclitaxel is an established CYP2C8 substrate (Monsarrat et al, 1993; Steed and Sawyer, 2007) and axitinib inhibits CYP2C8 in vitro, increases in plasma concentrations of paclitaxel when administered in combination with axitinib were possible. Thus, patients were administered escalating lead-in doses of axitinib (starting at $1 \mathrm{mg}$ b.i.d.) in sequential cohorts in combination with paclitaxel/carboplatin. Similar paclitaxel pharmacokinetics in the absence and presence of axitinib indicate that at clinically relevant plasma concentrations of axitinib, significant clinical CYP2C8 inhibition does not occur. In addition, there were no clinically apparent exacerbations of known paclitaxel toxicities.

Similarly, no overt changes in pharmacokinetics were observed between axitinib and cisplatin, carboplatin or gemcitabine and its metabolite dFdU, although interactions were not anticipated since axitinib is metabolised via pathways that are distinct from these agents. Both carboplatin and cisplatin are eliminated by glomerular filtration (Duffull and Robinson, 1997; Yao et al, 2007). Gemcitabine $\left(2^{\prime}, 2^{\prime}\right.$-difluorodeoxycytidine) is sequentially phosphorylated intracellularly by deoxycytidine kinase and converted to di- and triphosphate products. Observed plasma concentrations of axitinib in combination with either paclitaxel/carboplatin or gemcitabine/cisplatin were consistent with those reported in other phase I studies of axitinib as monotherapy or in combination with chemotherapy (Rugo et al, 2005; Sharma et al, 2010). Plasma exposures observed in this study of paclitaxel, carboplatin (PUF), cisplatin (PUF) and gemcitabine when administered alone were similar to those previously reported in the literature (VillalonaCalero et al, 2004; Kobayashi et al, 2007; Ricart et al, 2008; Okamoto et al, 2010).

Combinations of bevacizumab with chemotherapy have shown promising results in phase III studies of different tumour types; however, randomised trials of tyrosine kinase inhibitors targeting VEGF receptors in combination with chemotherapy have not shown a benefit for these combinations. Although the efficacy data for axitinib in combination with chemotherapy reported here are encouraging, they are exploratory, as would be expected from any phase I trial. The number of patients in each cohort was small, making it difficult to draw any definitive conclusions about the utility of axitinib combined with paclitaxel/carboplatin or gemcitabine/cisplatin in these patient populations. Nevertheless, they offer direction for ongoing and future clinical studies with sufficient statistical power for comprehensive analysis of the safety and efficacy of these combinations for the treatment of various cancers.

In conclusion, axitinib at a starting dose of $5 \mathrm{mg}$ b.i.d. may be combined with paclitaxel/carboplatin or gemcitabine/cisplatin at standard doses, with no apparent overlapping toxicities and no overt changes in plasma pharmacokinetic parameters. Both combinations showed antitumour activity in patients with advanced solid tumours, including squamous cell NSCLC. Phase II studies of axitinib in combination with paclitaxel/carboplatin, gemcitabine/cisplatin and pemetrexed/cisplatin for NSCLC were recently completed. 


\section{ACKNOWLEDGEMENTS}

This study was sponsored by Pfizer Inc. Support was provided in part by National Institutes of Health grant P30 CA006927 to the Fox Chase Cancer Center. We thank the patients who participated in this study and the physicians who referred them, as well as the

\section{REFERENCES}

Berns EM, Klijn JG, Look MP, Grebenchtchikov N, Vossen R, Peters H, Geurts-Moespot A, Portengen H, van Staveren IL, Meijer-van Gelder ME, Bakker B, Sweep FC, Foekens JA (2003) Combined vascular endothelial growth factor and TP53 status predicts poor response to tamoxifen therapy in estrogen receptor-positive advanced breast cancer. Clin Cancer Res 9: 1253-1258

Brown LF, Berse B, Jackman RW, Tognazzi K, Manseau EJ, Dvorak HF, Senger DR (1993) Increased expression of vascular permeability factor (vascular endothelial growth factor) and its receptors in kidney and bladder carcinomas. Am J Pathol 143: 1255-1262

Burris 3rd HA (2009) Shortcomings of current therapies for non-small-cell lung cancer: unmet medical needs. Oncogene 28(Suppl 1): S4-S13

Cohen EE, Rosen LS, Vokes EE, Kies MS, Forastiere AA, Worden FP, Kane MA, Sherman E, Kim S, Bycott P, Tortorici M, Shalinsky DR, Liau KF, Cohen RB (2008) Axitinib is an active treatment for all histologic subtypes of advanced thyroid cancer: results from a phase II study. J Clin Oncol 26: 4708-4713

Duffull SB, Robinson BA (1997) Clinical pharmacokinetics and dose optimisation of carboplatin. Clin Pharmacokinet 33: 161-183

Hu-Lowe DD, Zou HY, Grazzini ML, Hallin ME, Wickman GR, Amundson K, Chen JH, Rewolinski DA, Yamazaki S, Wu EY, McTigue MA, Murray BW, Kania RS, O'Connor P, Shalinsky DR, Bender SL (2008) Nonclinical antiangiogenesis and antitumor activities of axitinib (AG-013736), an oral, potent, and selective inhibitor of vascular endothelial growth factor receptor tyrosine kinases 1, 2, 3. Clin Cancer Res 14: 7272-7283

Hurwitz H, Fehrenbacher L, Novotny W, Cartwright T, Hainsworth J, Heim W, Berlin J, Baron A, Griffing S, Holmgren E, Ferrara N, Fyfe G, Rogers B, Ross R, Kabbinavar F (2004) Bevacizumab plus irinotecan, fluorouracil, and leucovorin for metastatic colorectal cancer. $N$ Engl J Med 350: 2335-2342

Ikeda N, Adachi M, Taki T, Huang C, Hashida H, Takabayashi A, Sho M, Nakajima Y, Kanehiro H, Hisanaga M, Nakano H, Miyake M (1999) Prognostic significance of angiogenesis in human pancreatic cancer. $\mathrm{Br} \mathrm{J}$ Cancer 79: 1553-1563

Jain M, Townsend RR (2007) Chemotherapy agents and hypertension: a focus on angiogenesis blockade. Curr Hypertens Rep 9: 320-328

Keedy VL, Sandler AB (2007) Inhibition of angiogenesis in the treatment of non-small cell lung cancer. Cancer Sci 98: 1825-1830

Kobayashi M, Oba K, Sakamoto J, Kondo K, Nagata N, Okabayashi T, Namikawa T, Hanazaki K (2007) Pharmacokinetic study of weekly administration dose of paclitaxel in patients with advanced or recurrent gastric cancer in Japan. Gastric Cancer 10: 52-57

Martin LP, Kozloff MF, Herbst RS, Samuel TA, Kim S, Rosbrook B, Tortorici M, Chen Y, Tarazi J, Olszanski AJ, Rado T, Starr A, Cohen RB (2012) Phase I study of axitinib combined with paclitaxel, docetaxel or capecitabine in patients with advanced solid tumours. $\mathrm{Br} \mathrm{J}$ Cancer; doi:10.1038/bjc.2012.407; e-pub ahead of print

Miller K, Wang M, Gralow J, Dickler M, Cobleigh M, Perez EA, Shenkier T, Cella D, Davidson NE (2007) Paclitaxel plus bevacizumab versus paclitaxel alone for metastatic breast cancer. $N$ Engl J Med 357: 2666-2676

Monsarrat B, Alvinerie P, Wright M, Dubois J, Gueritte-Voegelein F, Guenard D, Donehower RC, Rowinsky EK (1993) Hepatic metabolism and biliary excretion of Taxol in rats and humans. J Natl Cancer Inst Monogr 39-46

Moore M, Hirte HW, Siu L, Oza A, Hotte SJ, Petrenciuc O, Cihon F, Lathia C, Schwartz B (2005) Phase I study to determine the safety and pharmacokinetics of the novel Raf kinase and VEGFR inhibitor BAY 439006, administered for 28 days on/7 days off in patients with advanced, refractory solid tumors. Ann Oncol 16: 1688-1694

Okamoto I, Miyazaki M, Morinaga R, Kaneda H, Ueda S, Hasegawa Y, Satoh T, Kawada A, Fukuoka M, Fukino K, Tanigawa T, Nakagawa K study coordinators and data managers, Shelley Mayfield and Carol Martins at Pfizer Inc. for support of the study conduct, and Gamal ElSawah, Pfizer Medical Affairs, for his review of the manuscript. Medical writing support was provided by Joanna Bloom, of UBC Scientific Solutions (Southport, CT, USA) and Christine Arris at ACUMED (Tytherington, UK) and was funded by Pfizer Inc.
(2010) Phase I clinical and pharmacokinetic study of sorafenib in combination with carboplatin and paclitaxel in patients with advanced non-small cell lung cancer. Invest New Drugs 28: 844-853

Reck M, von Pawel J, Zatloukal P, Ramlau R, Gorbounova V, Hirsh V, Leighl N, Mezger J, Archer V, Moore N, Manegold C (2010) Overall survival with cisplatin-gemcitabine and bevacizumab or placebo as firstline therapy for nonsquamous non-small-cell lung cancer: results from a randomised phase III trial (AVAiL). Ann Oncol 21: 1804-1809

Ricart AD, Berlin JD, Papadopoulos KP, Syed S, Drolet DW, QuaratinoBaker C, Horan J, Chick J, Vermeulen W, Tolcher AW, Rowinsky EK, Rothenberg ML (2008) Phase I, pharmacokinetic and biological correlative study of OSI-7904L, a novel liposomal thymidylate synthase inhibitor, and cisplatin in patients with solid tumors. Clin Cancer Res 14: 7947-7955

Rini BI, Wilding G, Hudes G, Stadler WM, Kim S, Tarazi J, Rosbrook B, Trask PC, Wood L, Dutcher JP (2009) Phase II study of axitinib in sorafenib-refractory metastatic renal cell carcinoma. J Clin Oncol 27: $4462-4468$

Rixe O, Bukowski RM, Michaelson MD, Wilding G, Hudes GR, Bolte O, Motzer RJ, Bycott P, Liau KF, Freddo J, Trask PC, Kim S, Rini BI (2007) Axitinib treatment in patients with cytokine-refractory metastatic renalcell cancer: a phase II study. Lancet Oncol 8: 975-984

Rugo HS, Herbst RS, Liu G, Park JW, Kies MS, Steinfeldt HM, Pithavala YK, Reich SD, Freddo JL, Wilding G (2005) Phase I trial of the oral antiangiogenesis agent AG-013736 in patients with advanced solid tumors: pharmacokinetic and clinical results. J Clin Oncol 23: 5474-5483

Saad RS, Liu YL, Nathan G, Celebrezze J, Medich D, Silverman JF (2004) Endoglin (CD105) and vascular endothelial growth factor as prognostic markers in colorectal cancer. Mod Pathol 17: 197-203

Saltz LB, Clarke S, Diaz-Rubio E, Scheithauer W, Figer A, Wong R, Koski S, Lichinitser M, Yang TS, Rivera F, Couture F, Sirzen F, Cassidy J (2008) Bevacizumab in combination with oxaliplatin-based chemotherapy as first-line therapy in metastatic colorectal cancer: a randomized phase III study. J Clin Oncol 26: 2013-2019

Sandler A, Gray R, Perry MC, Brahmer J, Schiller JH, Dowlati A, Lilenbaum R, Johnson DH (2006) Paclitaxel-carboplatin alone or with bevacizumab for non-small-cell lung cancer. N Engl J Med 355: 2542-2550

Scagliotti G, Novello S, von Pawel J, Reck M, Pereira JR, Thomas M, Abrao Miziara JE, Balint B, De Marinis F, Keller A, Aren O, Csollak M, Albert I, Barrios CH, Grossi F, Krzakowski M, Cupit L, Cihon F, Dimatteo S, Hanna N (2010) Phase III study of carboplatin and paclitaxel alone or with sorafenib in advanced non-small-cell lung cancer. J Clin Oncol 28: 1835-1842

Schiller JH, Larson T, Ou SH, Limentani S, Sandler A, Vokes E, Kim S, Liau K, Bycott P, Olszanski AJ, von Pawel J (2009) Efficacy and safety of axitinib in patients with advanced non-small-cell lung cancer: results from a phase II study. J Clin Oncol 27: 3836-3841

Sharma S, Abhyankar V, Burgess RE, Infante J, Trowbridge RC, Tarazi J, Kim S, Tortorici M, Chen Y, Robles RL (2010) A phase I study of axitinib (AG-013736) in combination with bevacizumab plus chemotherapy or chemotherapy alone in patients with metastatic colorectal cancer and other solid tumors. Ann Oncol 21: 297-304

Spano JP, Chodkiewicz C, Maurel J, Wong R, Wasan H, Barone C, Letourneau R, Bajetta E, Pithavala Y, Bycott P, Trask P, Liau K, Ricart $\mathrm{AD}$, Kim S, Rixe O (2008) Efficacy of gemcitabine plus axitinib compared with gemcitabine alone in patients with advanced pancreatic cancer: an open-label randomised phase II study. Lancet 371: 2101-2108

Steed H, Sawyer MB (2007) Pharmacology, pharmacokinetics and pharmacogenomics of paclitaxel. Pharmacogenomics 8: 803-815

Stinchcombe TE, Socinski MA (2009) Current treatments for advanced stage non-small cell lung cancer. Proc Am Thorac Soc 6: 233-241

Strumberg D, Richly H, Hilger RA, Schleucher N, Korfee S, Tewes M, Faghih M, Brendel E, Voliotis D, Haase CG, Schwartz B, Awada A, 
Voigtmann R, Scheulen ME, Seeber S (2005) Phase I clinical and pharmacokinetic study of the novel Raf kinase and vascular endothelial growth factor receptor inhibitor BAY 43-9006 in patients with advanced refractory solid tumors. J Clin Oncol 23: 965-972

The Medical Letter Online (2004) Two new drugs for colon cancer. Med Lett Drugs Ther 46: 46-48

Therasse P, Arbuck SG, Eisenhauer EA, Wanders J, Kaplan RS, Rubinstein L, Verweij J, Van Glabbeke M, van Oosterom AT, Christian MC, Gwyther SG (2000) New guidelines to evaluate the response to treatment in solid tumors. European Organization for Research and Treatment of Cancer, National Cancer Institute of the United States, National Cancer Institute of Canada. J Natl Cancer Inst 92: 205-216

Trotti A, Colevas AD, Setser A, Rusch V, Jaques D, Budach V, Langer C, Murphy B, Cumberlin R, Coleman CN, Rubin P (2003) CTCAE v3.0: development of a comprehensive grading system for the adverse effects of cancer treatment. Semin Radiat Oncol 13: 176-181
Villalona-Calero MA, Ritch P, Figueroa JA, Otterson GA, Belt R, Dow E, George S, Leonardo J, McCachren S, Miller GL, Modiano M, Valdivieso M, Geary R, Oliver JW, Holmlund J (2004) A phase I/II study of LY900003, an antisense inhibitor of protein kinase C-alpha, in combination with cisplatin and gemcitabine in patients with advanced non-small cell lung cancer. Clin Cancer Res 10: 6086-6093

Wu S, Chen JJ, Kudelka A, Lu J, Zhu X (2008) Incidence and risk of hypertension with sorafenib in patients with cancer: a systematic review and meta-analysis. Lancet Oncol 9: 117-123

Yao X, Panichpisal K, Kurtzman N, Nugent K (2007) Cisplatin nephrotoxicity: a review. Am J Med Sci 334: 115-124

Zhu X, Wu S, Dahut WL, Parikh CR (2007) Risks of proteinuria and hypertension with bevacizumab, an antibody against vascular endothelial growth factor: systematic review and meta-analysis. Am J Kidney Dis 49: 186-193

This work is published under the standard license to publish agreement. After 12 months the work will become freely available and the license terms will switch to a Creative Commons Attribution-NonCommercial-Share Alike 3.0 Unported License. 